\title{
Economics and the Legalisation of Drugs
}

\section{Chris Wilkims and Frank Scrimgeour}

$\mathrm{T}$ The debate over the future of idrug control policy has largely been political and ideological. Political presssure for the lberalisation of drug laws has come from those who use drugs: and from those who are sympathetic to the plight of drug users. Those of the libertarian persuasion have argued for the legalisation of drug use on the basis that drug use has largely private or individual consequences (Szasz, 1987; (Ostrowski, 1990). Political pressure for the maintenance of drug prohibition has come from those who morally object to recreational drug use, and from those who believe drug use has a significant impact on people other than the drufg user themselves, such as spouses, children, neighbours, and employers (Kleiiman and Saiger, 1990; Inciardi and Saum, 1996; Wilson, 1990). The difficulties; with obtaining impartial quantitative data on the effects of drug use, and the externt of drug relaed harms, has meant the debate has often been reduced to a stallemate, polarised around existing political and ideological viewpoints (Zinberg, 1987; Warner. 1993).

However, in recent years a growing number of policy commentators have attempted to present their argumtents concerning the future direction of drug control policy in an economic benesfitt-cost framwork (Warner, 1993). Policy commentators have framed their: arrguments in this way to improve the clarity and objectivity of their arguments, amd to avoid the political and ideological rhetoric of the past (Warner, 1993). A posiitive consequelce of the application of benefit-cost frameworks to the drug controll debate is benefit-cost analysis provides a clear measurable criteria to select the besst drug contol policy.

The development of a rigorrous criterion for the enactment of prohibition is important because a prohibition resstricts indivdual freedom by removing the right of citizens to legally undertake a prarticular activity and many related activities, and sanctions the use of force and inttrusive surveillance by the state to enforce the legal restrictions. Examples include the :arrest and inprisonment of those who violate the law, the confiscation of the propertty of convicted offenders, the imposition of travel restrictions on convicted offenderrs, personal and household searches of members of the public, and the search of financial records of members of the public. Historical studies of the enactment of the drrug prohibitions have found evidence of policies driven by racial fear, popular myth, and bureaucratic expansion, rather than

Chris Wilkins is a Research Feellow at the A'cohol and Public Health Research Unit (APHRU), Faculty of Mediiciine and Heath Science, University of Auckland, and Frank Scrimgeour is the Asssociate Deanof Research, University of Waikato Management School, University off Waikato. 
balanced scientific and social reserch (see Abel, 1980; Musto, 1973, Brecher, 1972).

This paper reviews and critiques the benefit-cost approaches that have been used in the drug control policy litrature, with particular attention paid to the criteria for socially efficient prohitition that emerges from different benefit-cost frameworks. In the final section of the paper the implications for drug control policy of recent advances in the tconomic theory of public policy are briefly discussed.

\section{Simple Applications of Benefit.Cost Analysis to Drug Control Policy}

A large number of policy commentators have used fairly simple benefit-cost frameworks to present the case for he maintenance of prohibition, or alternatively to present the case for the legalisation of drugs (Warner, 1993). The goal in these benefit-cost calculations is to demorstrate that a particular policy or policy change would generate a positive net social benefit. The gaps in the quantitative research for many variables and relationship; has meant these evaluations have largely been qualitative in nature.

The principal social benefit o legalising drug use is the elimination of the harmful illicit market for drugs (see Boaz, 1991; Ostrowski, 1990; 1991; Nadelmann, 1989; Dennis, 1990; Miron and Zwiebel, 1995; Hamowy, 1987; Krauss and Lazear, 1991; Clarke, 1999). The illicit market produces drugs of uncertain quality, leads to a marketcontrolled by violent criminals, and inflates the price of drugs forcing some users tc finance their drug use through street crime. A legal market for drugs would alow the authorities to regulate the sale and manufacture of drugs, and provide juyers and sellers with peaceful ways to resolve contractual disputes. Drug use wuld be safer because drug products would be produced according to manufacturing standards and be labelled as to potency and ingredients. Drug users would be zducated about safe consumption practices and have access to clean utensils for aiministration. The violence associated with the drug trade would be greatly reducel because participants would have access to the police and courts to resolve busines and contractual disputes. The fall in the price of drugs after legalisation would ıllow drug users to support their consumption habits without having to resort to crime or fall into poverty.

Opponents of the legalisation of drugs concede legalisation is likely to make drug use safer and undermine the riolent criminal element involved in the market, but counter that drug legalisation vould also lead to a significant increase in the number of people who would use drugs (see Kaplan, 1988; Kleiman and Saiger, 1990; Wilson, 1990; Inciardi and saum, 1996; Clarke, 1999). They point out the legalisation of drugs will significantly lower the price of drugs and make them much easier to purchase, which wil inevitably lead to an increase in the demand for drugs both by current users and rew users. Greater drug use must surely mean more drug-related social problems. 
The fall in the price of illicit drugs fdlowing legalisation is likely to be significant. It has been estimated that a gram of cocaine that sells on the American black market for US\$60-80 could be sold legtlly for as little as US\$3-4 (Kaplan, 1988; Kleiman and Saiger, 1990; Nadelman, 1989). A gram of heroin that sells on the black market for US\$340 could retail lgally for US\$5 (Michaels, 1987). While the price elasticity of illicit drugs is widly held to be inelastic, it is not zero, and is likely to be more elastic in the long term(see Michaels, 1987; Clarke, 1999). Finally, while the demand for drugs maybe ineastic for current users, it is likely to be more elastic for new users (see Krauss and Lazear, 1991; Clarke, 1999). Grossman and Chaloupka (1998) and Saffer and Chaloupka (1999) both discuss elasticties and participation rates.

Opponents of the legalisation of drugs have also questioned the extent to which the harmful illicit market will disappear followng legalisation. This will depend on the transaction costs associated with participiting in the legal market versus the transaction costs of participating in the illegd market. It could well be that for many participants the costs of participating inthe legal market exceed the costs of participation in the illegal market, and the antiopated decline in the illegal market is overstated. The illicit market may continue to thrive if taxation and regulation regimes are too strict (Keilman and Saiger, 1990; Jacobs, 1990). The persistence, and adaptation, of the illicit market for camabis has been an issue in South Australia where cannabis use and cannabis ciltivation have been reduced to civil offences (Sutton and McMillan, 1999).

The over-riding issue in the simple applictions of the benefit-cost framework, however, has been whether the social benefits of eliminating the illicit market for drugs will exceed the social costs of additionl new drug users. The decision to persist with the policy of prohibition, or alernatively to resort to legalisation, depends on the estimates of the size of the drug using population following legalisation. Drug prohibition should be mainained if the social costs of increased drug use exceed the social benefits of eliminating the illicit market in drugs. Alternatively, the legalisation of drugs is lesirable if the social benefits of eliminating the illicit market in drugs can be shown to exceed the social costs of increased drug use.

Even those in favour of the legalisation of drugs indicate their support for legalisation is subject to the size of the legal dng using population. Dennis (1990) concludes the legalisation of drugs would contine to produce a net social benefit as leng as drug use did not increase by more than 100 percent. Ostrowski (1990) calculates the legalisation of drugs would confor a net social benefit as long as drug use did not increase by more than 1,200 percert. Opponents of legalisation believe they have demonstrated drug prohibition shouk be maintained merely by suggesting there is a risk that legal drug use could reach tie consumption levels of alcohol and tcbacco (see Kleiman and Saiger, 1990; Kapla1, 1988; Wilson, 1990). 


\section{Pigouvian Benefit-Cost Approaches to Drug Control Policy.}

A number of economists have evaluated drugs control policy using Pigouvian Welfare Economics. This applies a more formal framework to the benefit-cost calculation.

The focus of the Pigouvian analysis of drug control policy is the external costs of drug use (see Culyer, 1973; Wagstaff and Maynard, 1988). The external costs of drug use are the costs imposed on third parties from private drug consumption. The external costs of drug use cause a divergemce between the private and social costs of drug use. Drug users consume drugs at: an inefficiently high level because they do not bear the full costs of their drug comsumption, that is, some costs are externalised to others. In order to maximise the social product, the state should intervene in the market to reduce the quantity of drugs consumed to the socially efficient level. This is achieved by imposing a tax on the level of the activity, known as a Pigouvian tax.

The Pigouvian framework indicates a zero drug consumption standard, that is, the outright prohibition of drugs, is socially efficient when the marginal social cost of drug use exceeds the marginal private benefiit of drug use for all quantities of drug consumption (Wagstaff and Maynard, 1988). Figure 1 presents the circumstances where the socially efficient level off drug consumption is zero.

\section{Figure 1: Socially Optimal Level of Drug; Consumption Equal to Zero}

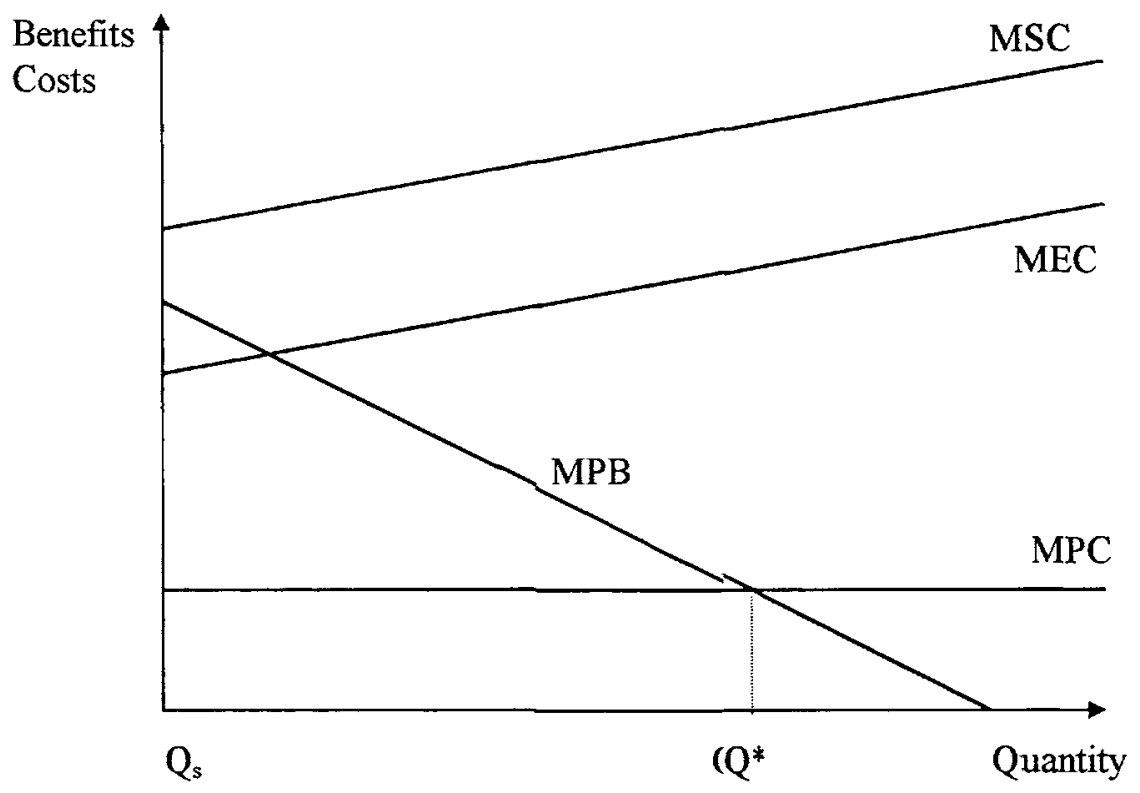

Source: Wagstaff and Maynard (19:8815). 
When drug users only considler the private benefits and costs of drug use they will choose to consume at $\mathrm{Q}^{*}$, where marginal benefits (MPB) and costs (MPC) are equal. If they are made to bear the full social cost of their drug use, that is, MPC plus the external costs (MEC) of drug use, they vill choose not to consume drugs at all. The socially efficient level of idrug consunption is zero at $Q_{s}$.

Culyer's (1973) discussion off the costs of illicit drug use, concluded only the 'physical harm drug users do tos others', and the 'corruption of minors', to be legitimate external costs of drug iuse. He spzculates that the physical harm drug users do to others may be significsantly reduced by the legalisation of drugs. Drug use is associated with violence lbecause drug users are often forced to commit crimes to pay for expensive black: market drugs. He points out if the price of illicit drugs were allowed to fall to their compettive level this kind of drug-related violence would be greatly reducedl. He recomnends (p. 456):

....full legalisation for adults, together wih 'zoning' regulations to protect minors from contact with adtult users, appears to be a probably efficient policy. Existing legislation: concerning public consumption of alcohol provides a basic model ffor the kird of institutional framework appropriate.

Wagstaff and Maynard (19818) believe tlere is a stronger Pigouvian case for the prohibition of drugs. They arrgue in the context of free public health care and unrestricted access to unemployment support, the health care costs of drug use and the loss of productivity from drugg use, are al relevant external costs of drug use. Wagstaff and Maynard treat drug;-related crime as an inherent consequence of drug use, and therefore consider it to bes a legitimate external cost of drug use. They also include the 'nuisance' and 'distresss' drug use's cause their families and friends as relevant external costs of drug usse. They e'en include the 'anxiety' illicit drug users cause parents of young peopple who are not currently using drugs but might begin doing so because of the cloose proximity of a drug using population, the so called 'the transmission effect', as : an external zost of drug use.

Wagstaff and Maynard claiim a zero lrug consumption standard is 'not unreasonable' given the difficultices with meauring the social harm of drug use, particularly the anxiety and distress of parerts and friends. They are unable to present any empirical studies that demonstrate the zero drug consumption standard is socially efficient, or that the costts of enforcing the zero standard do not exceed its benefits. They cite (p. 21) one stuudy of the sccial cost of drug abuse in the United States by the Research Triangle linstitute. The Institute estimated the cost of drug abuse in the United States to be UsS\$59.7 billion in 1983. These studies use a much broader concept of social cost than Pigouvianeconomics. Wagstaff and Maynard (1988:22) complain: 
In practice, studies often estimate social - rather than external - costs, and the estimates are always based on actual levels of consumption, rather than those which would obtain in the absence of government intervention.

\section{A Pigouvian Analysis of the Legalisation of Drugs}

In the simple applications of the benefit-cost framework to drug control policy, drug prohibition should be maintained and legalisation rejected, if the total social costs of increased drug use following legalisation exceed the total social benefits of eliminating the illegal market in drugs. The crucial issue that determines the social efficiency of drug prohibition in these evaluations is the number of people who would use drugs following legalisation. In the more sophisticated Pigouvian benefit-cost analysis, the number of people who would use drugs following legalisation is largely irrelevant to the social efficiency of drug prohibition. This can be demonstrated by using a Pigouvian analysis to illustrate the possible consequences of one legalisation scenario.

The legalisation of drugs will significantly lower the marginal private cost of drug use, by lowering the financial price of drugs, making it more convenient to purchase drugs, and by making drugs safer to consume. This is likely to lead to an increase in private drug consumption. Legalisation will also lower the marginal external cost of drug use, by reducing the need to commit crimes to finance a drug habit, and by eliminating the violence associated with drug trafficking. Figure 2 presents one possible legalisation scenario.

\section{Figure 2: The Legalisation of Drugs}

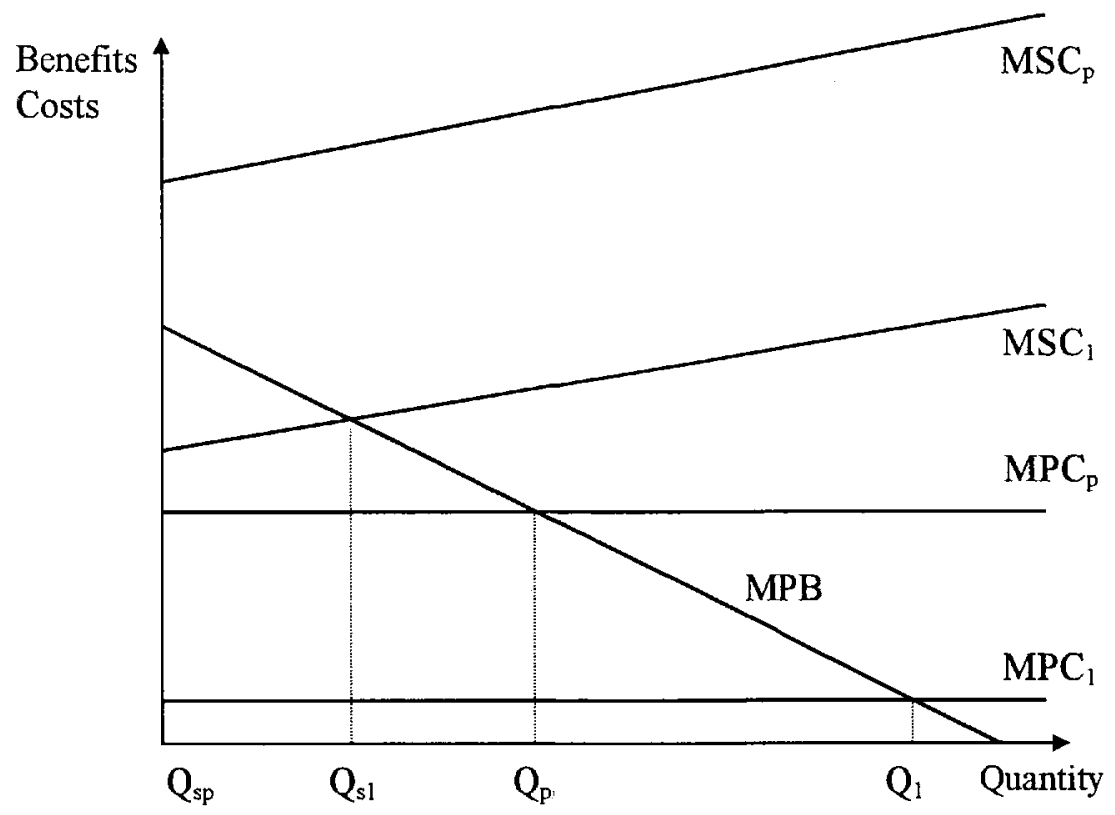


The marginal private cost of drug use falls from $\mathrm{MPC}_{\mathrm{p}}$ to $\mathrm{MPC}_{\mathrm{l}}$, which leads to an increase in private consumption of drugs from $Q_{p}$ to $Q_{1}$. The fall in the marginal external cost of drug use, together with the fall in the marginal private cost of drug use, leads to a fall in the marginal social cost of drug use from $\mathrm{MSC}_{\mathrm{p}}$ to $\mathrm{MSC}_{1}$. The marginal social cost curve $\left(\mathrm{MSC}_{1}\right)$ is now below the marginal private benefit curve for low levels of drug consumption, indicating the socially efficient level of drug consumption is positive, at $\mathrm{Q}_{\mathrm{s} \text { : }}$. It is the fall in the marginal social cost of drug use that dictates whether drug prohibition is socially efficient. The extent that drug consumption increases following legalisation, and subsequently how much the total social cost of drug use increases, has no impact on the social efficiency of drug prohibition.

The preceding discussion is however subject to two caveats. In a world of prohibition where MPB is greater than MPC there is still some trade in illegal drugs. Clearly for some consumers the benefits are greater than the costs. There is the associated dead weight losses they bear. If legalisation occurs the benefits of consumption presumably increase substantially (due to lower costs) but there will be regulation that may restrict their consumption, and the dead weight losses may in fact be larger in this new situation. Secondly, social costs associated with the policing of the legal market may in fact be larger than that of policing an illicit market.

The Pigouvian analysis indicates the prohibition of a product is only appropriate if the harm the product does to society is greater than the private benefit obtained from its consumption even when it is only consumed in very low quantities. The Pigouvian criterion for socially efficient prohibition is the marginal social harm of the product, not how many people choose to consume it. The importance of the distinction can be made clear by considering a less controversial product than recreational drugs.

Consider a campaign to prohibit motorcycle riding. A group of road safety campaigners recommend the prohibition of motorcycles because they are much more likely to be involved in road accidents than other vehicles, and because accidents involving motorcycles are much more likely to result in serious injury and fatality. The campaign is supported by a simple benefit-cost study that shows the total social cost of motorcycle riding significantly exceeds the total private benefit of motorcycle riding. A significant net total social benefit could be obtained if motorcycles were prohibited. Many readers, particularly the ones who enjoy riding motorcycles, are likely to strongly object to this analysis and recommendation.

A Pigouvian benefit-cost framework offers a much more sophisticated analysis. The focus of the Pigouvian analysis is the marginal social cost and the marginal private benefit of motorcycle riding, as opposed to the total social cost and total private benefit of motorcycle riding used in the simple application of benefitcost analysis. The prohibition of motorcycle riding is only socially efficient if it can 
be shown that the marginal social cost of motorcycle riding exceeds the marginal private benefit of motorcycle riding even for low llevels, or very controlled levels, of the activity. In practice, this criterion would require evidence that even when a motorcycle is ridden by a licensed rider, equippeed with the appropriate protective clothing, and ridden in a responsible manner, the social harm of motorcycle riding. still exceeds the private benefit of motorcycle riding. If this cannot be demonstrated the prohibition of motorcycles is not socially effiicient. The failure of the case for the prohibition of motorcycle riding should not prevent the state from taking steps to improve the safety of motorcycle riding, for example by requiring riders to obtain a motorcycle licence, wear a helmet, and have their motorcycles certified as safe to travel on the road.

Similarly with recreational drug use, the failure of the case for drug prohibition should not prevent the state from taking steps to improve the safety of drug consumption. Regulation should be develloped to make drug use safer for users and safer for the community. In Figure 2, there remains a significant gap between the unrestricted level of drug consumpttion $\left(Q_{1}\right)$ and the socially efficient level of drug consumption $\left(Q_{s}\right)$. Proposals for the legalisation of drug use do not generally refer to unrestricted access to drugss, at the very least minors are prevented from buying drugs and penalties are imposed for selling drugs to minors. The legalisation of drug use does not prevent: the authorities from adopting a regulatory and educational strategy to restrict drug consumption to a socially efficient level. This is the objective of government regulation concerning the sale and consumption of alcohol and tobacco, or the sale and use of poisons and explosives (see Kleiman and Saiger, 1990). The comparison between the prohibition of drugs and the legalisation of drugss should be a comparison between prohibition and a strictly regulated market for drugs, not a comparison between prohibition and an unregulated open market for dirugs.

Of course the scenario in Figure 2 is mere speculation - at present there is limited information on the marginal social cost amd marginal private benefit of drug use. The addictive characteristics of different drugs would also seem to be relevant as this would determine the ability of users to consume drugs at moderate levels. Finally, there are adjustment and enforcement costs to consider, of which we know little.

A number of important points emerge from the Pigouvian benefit-cost analysis of the legalisation of drugs:

- If the legalisation of drugs lead to more pecople consuming drugs the increase in the total social cost of drug use would be offset by a corresponding increase in the total private benefit of drug use. The private benefits of drug use are widely ignored in the simple applications; of benefit-cost analysis to drug control policy (Kleiman and Saiger, 1990). 
- Legal drug use will be safer fior drug consumers and less harmful to the public. The legalisation of drugs is likely to lower the marginal private cost of drug use and the marginal external cost of drug use.

- Legal drug use does not refer to an unregulated open market for drugs. The legalisation of drugs does not prevent the authorities from adopting a regulatory and educational strategy to make drug consumption safer for users and for the public.

\section{Ronald Coase and the Pigouvian Approach to Drug Control Policy}

Although the Pigouvian benefit-cost analysis is an improvement on the simple applications of the benefit-cost framework, Ronald Coase (1960) has demonstrated there are a number of conceptual problems with the Pigouvian approach to external harmful effects. It seems appropriate to end this paper by discussing how these conceptual problems may distort the Pigouvian analysis of drug control policy.

1. The Pigouvian analysis conceptualises the drug control problem solely as drug users imposing external harms on the non-drug using public, and thereby reducing total social welfare. By prohibiting drug use, the state is thought to be able to increase total sociall welfare. This view of the problem fails to appreciate that drug restrictioms also impose costs on society. Drug prohibition makes drugs more dangerous by removing manufacturing and quality controls, promotes addict street crime, creates a violent black market, consumes scarce law enforcement resources, errodes civil liberties, and exposes law enforcement agencies to corruption. Once these costs are taken into account it is no longer clear whether a reduction in! drug consumption will necessarily produce an increase in total social welfare. There appear to be ranges of enforcement where increasing effort is likelly to reduce social welfare by increasing the harm of the illicit market (Kleiman, 1992).

2. The Pigouvian analysis also ffails to appreciate that the external costs of drug use are merely a function of the institutional environment in which drugs are traded and consumed. Institutional reform can make private drug users bear more fully the social costs of their drug use. Drug use only creates an external health care cost if health carre is provided 'free' from general taxation via a public health system. The health care external cost of drug use could be much reduced, or even eliminated, if private drug users were made to pay for the health care services that are directly related to their drug use or made to pay higher health insurance premiums reflecting their greater risk of illness. Greater targeting of public health care services could reduce the health care 
external cost of drug use without having to prohibit drug use. ${ }^{1}$ The more fully private drug users bear the cost of their drug use, the stronger are the private incentives to reduce drug consumption to the socially efficient level.

3. The enactment of drug prohibition forces drugs to be produced, exchanged, and consumed, under illicit market conditions. Illicit market conditions inflate the external costs of drug use, by increasing the health risk of drugs and by forcing users to commit crimes to pay for expensive black market drugs, and create completely new external harms, for example, a violent black market, loss of civil liberties and police corruption. To avoid government intervention based on the unintended consequences of past government intervention, policy makers must evaluate the case for intervention in the drugs market on the basis of the external costs of drug use that would be produced under normal legal market conditions. At present the authorities use the external costs of drug use which are produced under illicit market conditions to justify the prohibition of drugs. This causes them to overstate the case for drug prohibition.

\section{Conclusion}

The Pigouvian benefit-cost analysis of drug control policy represents a significant improvement on the simple applications of the benefit-cost framework that are widely used in the policy literature. The Pigouvian criterion for socially efficient prohibition, based on the marginal social harm of a product, focuses the analysis on the social harm of the product itself. The Pigouvian criterion will only prohibit products and activities that are inherently extremely dangerous to the public, that is, when the marginal social cost of the product exceeds the marginal private benefit of the product even at very low, or controlled, levels of use.

The simple applications of the benefit-cost framework to the problem, that only consider the total social costs of an activity, lead to the focus on the number of people who use a product. Total social cost creates a misleading impression about the harm of a product. A product can produce a significant total social cost even if it is only moderately harmful, simply if a large number of people choose to use it. The appropriate response to moderately harmful products is to regulate their use to improve their safety, rather than prohibit them.

The critique of the Pigouvian tradition by Coase (1960) indicates even more progress is required to find an adequate framework to determine if a prohibition is socially efficient. Coase (1960) challenges us to view harmful effects as rights to harm, or rights not to be harmed. The goal in the Coasian approach is to find the institution and policy instrument that allocates these rights in a way that encourages the most efficient social outcomes. Comparison of institutional arrangements must

There are some obvious practical limitations to a targeting policy, such as the ability of drug users to pay for health care, the ability of the authorities to distinguish between health problems related to drug use and everyday health problems, etc (see Clarke, 1999). 
include the costs of institutional change, transaction costs, and any government/market failures with the new arrangement. There appears to be enormous potential for the application of Coase's ideas to the problem of socially efficient prohibition.

\section{References}

Abel, E. (1980), Marijuana - the first 12,000 years, Plenum Press, New York.

Boaz, D. (ed.) (1991), The Crisis in Drug Prohibition, Cato Institute, Washington D.C.

Brecher, E. (1972), Licit and lllicit Drugs, Little, Brown \& Company, Boston.

Byck, R. (1987), 'Cocaine, Marijuana, and the Meaning of Addiction', pp. 221-245 in R. Hamowy, (ed.) Dealing with Drugs: Consequences of Government Control, Lexington Books, Lexington.

Clarke, H. (1999), 'Public Provision of Heroin for Addicts', Agenda 6(3):195-210.

Coase, R. (1960), 'The Problem of Social Cost', Journal of Law and Economics 3(1):144.

Culyer, A. (1973), 'Should Social Policy Concern Itself with Drug Abuse?', Finance Quarterly 1(4):449-56.

Dennis, R. (1990), 'The Economics of Legalising Drugs', The Atlantic Monthly November:126-129.

Drug Policy Forum Trust (1997), Alternative Systems of Cannabis Control in New Zealand: A Discussion Paper, The Trust, Wellington.

Drug Policy Forum Trust (1998), New Zealand Should Regulate and Tax Cannabis Commerce: Final Report, New Zealand Drug Foundation (http://www.nzdf.org.nz).

Grossman, M. and F. Chaloupka (1998), 'The Demand for Cocaine by Young Adults: A Rational Addiction Approach', Journal of Health Economics 17(4):27-74.

Hamowy, R. (1987), 'Introduction: Illicit Drugs and Government Control', pp. 1-34 in R. Hamowy, (ed.) Dealing with Drugs: Consequences of Government Control, Lexington Books, Lexington.

Inciardi, J. and C. Saum (1996), 'Legalisation Madness', The Public Interest 123(Spring):72-82.

Kaplan J. (1988), 'Taking Drugs Seriously', The Public Interest 92(Summer):32-50.

Kleiman, M. and A. Saiger (1990), 'Drug Legalisation: The Importance of Asking the Right Question', Hofstra Law Review 18:527-65.

Kleiman, M. (1993), Against Excess: Drug Policy for Results, Basic Books, New York. 
Krauss, M. and E. Lazear (ed.) (1991), Searching for Alternatives: Drug-Control Policy in the United States, Hoover Institution Press, California.

Kuhn, C., S. Swartzwelder, and W. Wilson (1998), Buzzed: The Straight Facts About the Most Used and Abused Drugs From Alcohol to Ecstasy, W. W. Norton \& Co., New York.

Michaels, R. (1987), 'The Market for Heroin Before and After Legalisation', pp. 289-326 in R. Hamowy, (ed.) Dealing with Drugs: Consequences of Government Control, Lexington Books, Lexington.

Miron, J. and J. Zwiebel (1995), 'The Economic Case Against Drug Prohibition', Journal of Economic Perspectives 9(4):175-192.

Musto, D. (1973), The American Disease: Origins of Narcotic Control, Yale University Press, New Haven.

Nadelmann, E. (1989), 'Drug Prohibition in the United States: Costs, Consequences, and Alternatives', Science 245:939-47.

Ostrowski, J. (1990), 'The Moral and Practical Case for Drug Legalisation', Hofstra Law Review 18:607-702.

Ostrowski, J. (1991), 'Thinking about Drug Legalisation', pp. 45-76 in D. Boaz, (ed.) The Crisis in Drug Prohibition, Cato Institute, Washington D.C.

Saffer, H. and F. Chaloupka (1999), 'The Demand for Illicit Drugs', Economic Inquiry 37(3):401-11.

Sutton, A. and E. McMillan (1999), A Review of Law Enforcement and Other Criminal Justice Attitudes, Policies and Practices Regarding Cannabis Laws in South Australia, Commonwealth Department of Health and Aged Care, and the National Drug Strategy, AGPS, Canberra.

Wagstaff, A. and A. Maynard (1988), 'Economic Aspects of the Illicit Drug Market and Drug Enforcement Policies in the United Kingdom', HMSO, London (Home Office Research Study No. 95).

Warner, K. (1993), 'Legalising Drugs: Lessons from (and about) Economics', pp. 337357 in R. Bayer and G. Oppenheimer, (eds) Confronting Drug Policy: Illicit Drugs in a Free Society, Cambridge University Press, New York.

Wilson, J. (1990), 'Against the Legalisation of Drugs', Commentary 89(2):21-28.

The authors wish to thank the Editor and two anonymous referees for their comments. The views expressed in this article are those of the authors and are not necessarily shared by Alcohol and Public Health Research Unit, Auckland University or Waikato University. 